OECDpublishing

\title{
OVERCOMING EVIDENCE GAPS ON FOOD SYSTEMS
}

OECD FOOD, AGRICULTURE AND FISHERIES PAPER

July $2021 n^{\circ} \mathbf{1 6 3}$ 


\title{
OECD TRADE AND AGRICULTURE DIRECTORATE
}

\section{Overcoming Evidence Gaps on Food Systems}

\author{
Koen Deconinck, Céline Giner, Lee Ann Jackson and Lucinda Toyama
}

Food systems are expected to provide food security and nutrition, to contribute to the livelihoods of millions, and to do so in an environmentally sustainable way. The broad outlines of these challenges are clear, and in many cases evidence exists on how better policies can improve the performance of food systems. But there are considerable gaps in data and evidence. This paper provides a panoramic overview of different types of evidence gaps on food systems and their causes, and makes the case that better evidence is needed to enable better policies. At the same time, evidence will never be complete. Policy makers and the research community thus need to adopt a pragmatic approach, focusing on where better evidence can make the biggest difference.

Keywords: Data, sustainable development goals, indicators, evidence gap maps, impact assessment

JEL Codes: C80, Q01, Q10

\section{Acknowledgements}

In addition to comments received from colleagues and delegates, the authors wish to acknowledge helpful discussions with and comments from Ellie Avery, Dustin Benton, Ousmane Badiane, Chris Béné, Valerie Bizier, Marina Bortoletti, Joachim von Braun, Luc Christiaensen, Alan Dangour, Ed Davey, Jessica Fanzo, Corinna Hawkes, Chris Hegadorn, Tom Hertel, Mike Hoffman, Fabio Isoldi, Marjo Kasanko, Clea KaskeKuck, Micheline Khan, Olav Kjorven, David Laborde, Uma Lele, Rachel Loopstra, Julia Marton-Lefevre, Will Masters, Alan Matthews, Cecil Max Haverkamp, Aline Mosnier, Wilfred Legg, Stella Nordhagen, Kelly Parsons, Jyotsna Puri, Navin Ramankutty, Guido Schmidt-Traub, Johan Selenius, Aman Sidhu, Greg Sixt, Nichole Tichenor Blackstone, Hugo Valin, Patrick Webb, and Gavin Wren, as well as participants at the OECD/CGIAR/Akademiya2063 event "Science for Food Systems Policy"', that took place on 18 June 2021. 


\section{Table of Contents}

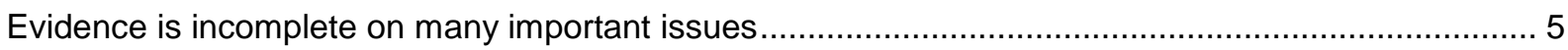

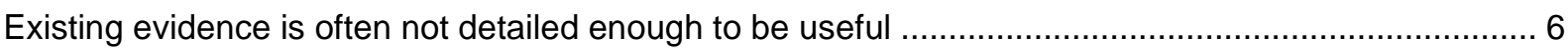

Inconsistent methodologies may prevent comparison of available evidence .......................................... 8

Evidence may be fragmented across different public and private actors ......................................... 8

Synergies, trade-offs, and spatial linkages are not always well understood ........................................ 9

Evidence on the effectiveness of policy instruments is especially lacking ......................................... 10

A pragmatic approach focuses on where better evidence can make the biggest difference ................ 12

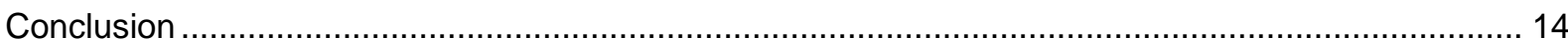

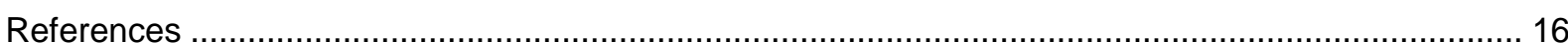

\section{Tables}

Table 1. Reporting rates for 20 food and agriculture-related SDG indicators

\section{Figures}

Figure 1. Example of an Evidence Gap Map (EGM) on agricultural innovation 


\section{Key messages}

- Making better policies for food systems will require overcoming evidence gaps:

○ ....on the extent, characteristics and drivers of policy issues

- ....on the effectiveness of different policy instruments and their synergies and trade-offs

- ...on how a policy would affect stakeholders, and on citizens' policy preferences

- There are different types of evidence gaps, with different implications

- Evidence is incomplete on many important issues

- Where evidence exists, it is often not detailed enough to be useful (for example, not segmented by socio-economic status)

- Inconsistent methodologies may prevent comparison of available evidence

- Evidence may be fragmented across different public and private actors

- Evidence on synergies and trade-offs and on the effectiveness of policy instruments is especially lacking

- A pragmatic way forward is to focus on where better evidence can make the biggest difference

- Information is costly to collect, and will never be perfect

- Needs can be prioritised, e.g. using evidence gap maps

- New technologies and institutional innovations can help

\section{Making better policies for food systems will require reducing evidence gaps}

Around the world, food systems are facing a daunting triple challenge, as they are expected to provide food security and nutrition for a growing population, to contribute to the livelihoods of millions of farmers, fishers and other workers along food supply chains, and to achieve these goals in an environmentally sustainable way that conserves natural resources and mitigates climate change (OECD, 2021 $\left.{ }_{[1]}\right)$. The UN Food Systems Summit, to be held in September 2021, demonstrates the growing realisation that meeting this triple challenge is essential to achieve the Sustainable Development Goals.

The concept of food systems highlights important interaction effects between different policy areas which have historically often been treated in isolation. For example, food systems draw attention to possible connections between agricultural policies and environmental or health outcomes. Because of these interaction effects, better policies for food systems should be coherent - that is, designed so that efforts in one policy area reinforce those in another area, or at least do not counteract them (OECD, 2021 ${ }_{[1]}$ ) (Parsons and Hawkes, 2019 $[2]$ ).

Making better policies for food systems is made complicated by frictions related to facts, interests and values (OECD, 2021 $\left.{ }_{[1]}\right)$. Disagreements over facts can occur if there is insufficient information or if there are gaps between public perception and the evidence. Without a shared understanding of the facts, it is difficult to achieve agreement on the best course of action. But any proposed policy change will also tend to create both winners and losers. These diverging interests are a further source of friction, as interest groups will try to influence the policy process to move policies in their preferred direction. Making better policies may also be complicated by differences in values people hold. This makes it difficult to agree on societal priorities and on how trade-offs regarding food systems should be decided. Facts, interests, and values can interact in complex ways: for example, what people consider as relevant facts may depend on their interests and values. Frictions related to facts, interests, and values can be managed by using good practices in the policy process, although none can guarantee success (OECD, $\left.2021_{[1]}\right)$. 
At least in theory, disagreements over facts should be easy to resolve through the collection and sharing of data and evidence (even if in reality some uncertainty will always remain). Much is known about the challenges facing food systems, and about possible initiatives to improve their performance, as reflected by a growing number of reports (OECD, 2021[1]) (FAO, 2018[3]) (Fanzo et al., 2020[4]) (HLPE, 2017[5]) (Parsons and Hawkes, 2018[6]) (FABLE, 2019[7]) (TEEB, 2018[8]) (Bene et al., 2018[9]) (Gladek et al., 2017[10]) (Global Panel on Agriculture and Food Systems for Nutrition, 2016[11]) (Parsons and Hawkes, 2019 $\left.{ }_{[2]}\right)\left(\right.$ SAPEA, 2020[12]) $\left(\right.$ UNEP/SFSP, 2019 $\left[9_{[13]}\right)$ (Willett et al., 2019 $\left.{ }_{[14]}\right)$. Yet, despite these contributions, there remain important gaps in our knowledge, and this often prevents making better policies. In order to design effective policies, it is thus essential to address these "evidence gaps". The term "evidence" is used here in a broad sense, including statistical data and scientific findings.

Evidence gaps may exist regarding the extent, characteristics and drivers of policy issues, making it difficult to know how serious the problems are or what causes them. But evidence gaps may also exist regarding the effectiveness of different policy instruments and their synergies and trade-offs. This in turn makes it difficult to know how ambitious policy makers can be, which concrete initiatives can be undertaken, and what the likely positive or negative spill overs on other policy objectives will be. These different types of evidence gaps may be interlinked: a lack of information on the extent of problems, or the various policies in place in different countries, may in turn make it difficult to assess the effectiveness of different policy instruments. In addition, there may also be evidence gaps around interests and values, for example on how a proposed initiative would affect different stakeholders, or what matters more to citizens in the context of the relative importance of competing objectives for food systems policies.

The COVID-19 pandemic has highlighted areas where better evidence is particularly important for responding to crises and building resilience for the future. For instance, it is crucial to have better evidence on where vulnerable people are located, the extent to which they are disproportionately impacted by shocks, and the kinds of safety nets that are needed to reduce vulnerability.

In many cases, the problem is not an absolute lack of evidence, but rather that the available evidence is not sufficiently detailed - for example, evidence might have insufficient geospatial granularity, may not be disaggregated across socio-economic groups, or may not have the right frequency or time horizon. Similarly, evidence may exist but may be fragmented across different public or private actors. Evidence may also be generated using different methodologies, making it difficult to compare across countries, across different groups of people, or over time.

At the same time, policy makers will never have perfect information. Collecting further data and evidence comes at a cost, takes time, and requires technical expertise which may not always be available. More fundamentally, the precise effects of any policy intervention are inherently uncertain, and can only be approximated ex ante based on experience in other times or places, or based on theoretical insights. Furthermore, postponing a policy decision until more information is available is itself a decision which is potentially costly, for example by creating delays. Completely resolving all evidence gaps is therefore not a reasonable goal. Rather, the goal is to pragmatically identify the evidence gaps where additional efforts can make the biggest impact, and to find effective ways of reducing those evidence gaps to the point where policy makers can feel comfortable in deciding on a course of action. Thus, an "evidence gap" can be defined as the gap between the evidence policy makers would need to decide on a course of action, and the actual evidence currently available to them.

Food systems are not unique in facing evidence gaps, but several characteristics do suggest that evidence gaps may be especially pronounced in food systems. First, the term "food systems" is broad, potentially encompassing food security and nutrition issues for more than seven billion people, livelihoods of millions of people (many of whom are working in informal conditions), and environmental effects along several dimensions (greenhouse gas emissions, biodiversity, water pollution, etc). Second, food systems are characterised by diversity, making it difficult to extrapolate from findings in one context to draw conclusions about other contexts. Third, by its very nature the concept of "food systems" emphasises spillover effects across different domains (agricultural production, environmental sustainability, food security and nutrition, etc.), and these spillovers themselves vary depending on local context and spatial scales. This greatly increases the number of possible effects to be investigated, and hence the likelihood of evidence gaps.

With only ten years left to meet the Sustainable Development Goals, the importance of addressing evidence gaps on food systems is clear. Fortunately, there is growing momentum. Several promising initiatives are trying to identify and prioritise evidence gaps, while digital technologies can drastically lower 
the cost of collecting some types of evidence. There is also a broader shift towards more evidence-based policy making, as demonstrated by the growing use of randomised controlled trials (RCTs) to obtain more precise estimates on the impact of social and economic policies.

The goal of this note is not to provide an exhaustive list of evidence gaps on food systems, but rather to illustrate the various types of evidence gaps policy makers must contend with, while offering suggestions about practical approaches that could be used to prioritise and address these evidence gaps. Future work by the OECD will explore some pressing evidence gaps in more detail and will also provide more discussion on these practical approaches.

\section{Evidence is incomplete on many important issues}

Evidence is incomplete on many dimensions of food systems, as illustrated by reporting gaps on foodrelated Sustainable Development Goals (SDGs). The seventeen SDGs have been translated into 169 targets, which are in turn tracked through 231 indicators. Of these, 21 food and agriculture-related indicators are tracked by the Food and Agriculture Organization (FAO). Table 1 shows for each of these indicators the share of countries reporting data in recent years (2015-2019). (Data on indicator 14.4.1, the proportion of fish stocks within biologically sustainable levels, is usually reported at global or regional level and hence not shown in this table).

\section{Table 1. Reporting rates for 20 food and agriculture-related SDG indicators}

\begin{tabular}{|c|c|}
\hline SDG indicators under FAO custodianship & $\begin{array}{l}\text { Share of countries } \\
\text { reporting }\end{array}$ \\
\hline 15.1.1 Forest area as a percentage of total land area & $100.00 \%$ \\
\hline 15.4.2 Mountain Green Cover Index & $100.00 \%$ \\
\hline 2.1.1 Prevalence of Undernourishment & $82.10 \%$ \\
\hline 2.c.1 Indicator of (food) price anomalies & $78.10 \%$ \\
\hline 15.2.1 Progress towards sustainable forest management & $69.20 \%$ \\
\hline 6.4.2 Level of water stress: freshwater withdrawal as a proportion of available freshwater resources & $64.30 \%$ \\
\hline $\begin{array}{l}\text { 14.b.1 Progress by countries in the degree of application of a legal / regulatory / policy /institutional } \\
\text { framework which recognises and protects access rights for small-scale fisheries }\end{array}$ & $61.10 \%$ \\
\hline 2.a.1 The agriculture orientation index for government expenditures & $58.20 \%$ \\
\hline $\begin{array}{l}\text { 14.6.1 Progress by countries in the degree of implementation of international instruments aiming to combat } \\
\text { illegal, unreported and unregulated fishing }\end{array}$ & $56.00 \%$ \\
\hline $\begin{array}{l}\text { 14.7.1 Sustainable fisheries as a percentage of GDP in Small Island Developing States, Least Developed } \\
\text { Countries and all countries }\end{array}$ & $54.10 \%$ \\
\hline $\begin{array}{l}\text { 2.5.1.a Number of plant genetic resources for food and agriculture secured in medium or long term } \\
\text { conservation facilities }\end{array}$ & $50.50 \%$ \\
\hline $\begin{array}{l}\text { 2.1.2 Prevalence of moderate or severe food insecurity in the population, based on the Food Insecurity } \\
\text { Experience Scale }\end{array}$ & $45.90 \%$ \\
\hline 2.5.2 Proportion of local breeds classified as being at risk of extinction & $39.30 \%$ \\
\hline 6.4.1 Change in water use efficiency over time & $26.00 \%$ \\
\hline $\begin{array}{l}\text { 2.5.1.b Number of animal genetic resources for food and agriculture secured in medium or long term } \\
\text { conservation facilities }\end{array}$ & $8.70 \%$ \\
\hline $\begin{array}{l}\text { 5.a.2 Proportion of countries where the legal framework (including customary law) guarantees women's } \\
\text { equal rights to land ownership and/or control }\end{array}$ & $8.00 \%$ \\
\hline $\begin{array}{l}\text { 5.a.1 (a) Percentage of people with ownership or secure rights over agricultural land (out of total } \\
\text { agricultural population), by sex; and (b) share of women among owners or rights-bearers of agricultural } \\
\text { land, by type of tenure }\end{array}$ & $3.00 \%$ \\
\hline 2.3.2 Average income of small-scale food producers, by sex and indigenous status & $2.60 \%$ \\
\hline 2.3.1 Volume of production per labour unit by classes of farming / pastoral / forestry enterprise size & $1.50 \%$ \\
\hline 2.4.1 Proportion of agricultural area under productive and sustainable agriculture & $0.00 \%$ \\
\hline 12.3.1 Food Loss Index & $0.00 \%$ \\
\hline
\end{tabular}

Source: FAO (2020[15]). 
For many of these indicators, important gaps exist. For example, in recent years no countries reported complete data for the food loss index or the proportion of agricultural area under productive and sustainable agriculture, and only a handful of countries reported disaggregated information on average income of small-scale producers. For some of these indicators, reporting gaps reflect the difficulties in reaching internationally agreed methodologies, some of which were only established recently, as discussed below. But for many other indicators, country coverage is also incomplete; only four indicators are available for at least $75 \%$ of countries.

The SDGs are high on the policy agenda, and indicators for the SDGs are supported by coordinated global efforts to create internationally agreed methodologies and to support countries with the collection and dissemination of the relevant data. The fact that important reporting gaps remain despite these efforts suggests that internationally comparable indicators may be even more incomplete in areas not explicitly covered by SDG indicators. At the same time, reporting gaps do not necessarily indicate an absolute lack of information, as partial evidence or alternative indicators might be available. But even then, available evidence may not be sufficiently detailed to be useful for policy makers, as discussed in the next sections.

\section{Existing evidence is often not detailed enough to be useful}

To be useful for policy makers, data and evidence need to be relevant to the issue at hand, sufficiently detailed to understand the issue, and collected sufficiently frequently (SDSN TRENDS, 2019[16]). Across all dimensions of the triple challenge, existing evidence on the extent and characteristics of policy issues often suffer from a lack of detail. For example, there might be a lack of geospatial granularity when evidence is only available at the national level while effective policy making requires evidence at a more fine-grained level (e.g. regional, farm level, plot level). Another example is when evidence does not differentiate between different socio-economic groups (e.g. by gender, age, income, ethnicity, location, and so on), and is therefore unable to provide detailed information regarding e.g. the prevalence of nutrition problems (Placzek, 2021 $[17])$. Similarly, data may have the wrong frequency (e.g. yearly data when monthly data would be needed) or may be outdated (which is especially likely in rapidly changing situations, e.g. regions characterised by rapid population growth, urbanisation, and food systems transformation). In other cases, available evidence may only capture certain aspects of an issue but not others.

Lack of detail is common for datasets which aim to provide cross-country comparable information, as is true for the SDG indicators listed above. In an effort to provide internationally harmonised data, concessions need to be made on the level of detail. For example, international data on agri-environmental indicators such as nutrient balances is often not geospatially explicit. However, the environmental performance of agriculture is highly context-dependent, and national averages can mask significant subnational variability $\left(\mathrm{OECD}, 2020_{[18]}\right)\left(\mathrm{OECD}, 2019_{[19]}\right)$. Especially in large countries with diverse agroecological conditions, production patterns, and management strategies, a single national data point lacks the level of detail needed to develop effective policies. ${ }^{1}$

On many questions related to nutrition problems, it is costly to obtain detailed evidence disaggregated by socio-economic groups, which would be useful in targeting policy approaches. For example, it is clear that globally there are widespread deficiencies of micronutrients such as iron, zinc, or vitamin A (Development Initiatives, 2018[20]). However, there is a lack of disaggregated data on micronutrient deficiencies in vulnerable populations like children, adolescent girls, and women, while other segmentations (e.g. by income and age groups) are also lacking. In response to these gaps, researchers have often used proxies, which can shed some light on the extent of the problem but are not sufficiently detailed to be useful in policy design. ${ }^{2}$

\footnotetext{
${ }^{1}$ Given the heterogeneity and diversity of food systems, relevant knowledge is often highly local. In recent years, there has been a growing appreciation of such "local" knowledge (e.g. locally adapted production practices) held by Indigenous Peoples. In 2020, FAO launched the Global Hub on Indigenous Peoples' Food Systems (http://www.fao.org/indigenous-peoples/global-hub/en/) to help bridge the gap between scientific and Indigenous Peoples' knowledge on food systems.

2 Despite these shortcomings, some progress has been made in filling evidence gaps on micronutrient deficiencies. The WHO Vitamin and Mineral Nutrition Information System (VMNIS) Micronutrients database brings together
} 
The available estimates on the Prevalence of Undernourishment (PoU) are another example where crosscountry comparable indicators unfortunately do not allow a more disaggregated view. The PoU indicator is defined as the probability that a randomly selected member of a particular population has less food to consume than they require for an active and healthy life (Wanner et al., 2014[21]). In theory, this indicator could be estimated for any sub-group of interest as long as there exists representative survey data covering this sub-group. In reality, conducting such surveys is costly and time-consuming, leading to important evidence gaps not only for specific sub-groups but also for many countries. To reduce these gaps, national PoU rates are estimated by combining data on national food availability (based on FAO's Food Balance Sheets) with estimates of the inequality of food consumption across households to arrive at an approximate distribution of food consumption in society. This approach then allows estimating the share of the population for whom food intake falls below the minimum dietary energy requirement (MDER), which is based on biophysical models on energy requirements and the make-up of the population in terms of age and gender (FAO, IFAD, UNICEF, WFP, and WHO, 2020[22]). The estimation of national PoU rates is thus an example of a creative use of different data sources to shed light on population-level food insecurity despite a lack of detailed evidence. However, the methodology used in constructing the national PoU estimates makes it difficult to go much deeper, e.g. in understanding the actual distribution of consumption of various types of food, or in arriving at a more fine-grained socio-economic disaggregation. ${ }^{3}$

In yet other cases, existing evidence may capture some aspects of an issue but may not cover all the relevant dimensions. This is often the case with information on farmer livelihoods in high-income countries. In many of these countries, government policies have an explicit aim to support the incomes of farmers. Yet, work by the OECD has often found that data on the income and wealth of farmers is incomplete, making it difficult to get a clear view on their actual economic conditions (see e.g. OECD (2019[23])). Data on off-farm incomes and on household wealth are typically missing (Hill and Bradley, 2015[24]). In some countries, the definition of a "farm household" might imply that a household is not included if its off-farm income exceeds a certain share of total income (OECD, 2003[25]). Yet, off-farm income appears to make up a growing share of income in OECD countries; for instance, in Ireland $52 \%$ of farm households have income from off-farm employment in 2019 (OECD, 2019[26]). Missing or omitted data on off-farm income implies that existing evidence on livelihoods may dramatically understate actual incomes for farm households (OECD, 2003[25]) (Blandford, 2007[27]). Other statistical sources for information on household incomes may also not accurately capture incomes of farm households: in some countries, farmers are exempt from paying income taxes when they earn less than a certain threshold (OECD, 2020[28]), and nationally representative household surveys may not include a sufficient number of farm households to make accurate estimates (Hill and Bradley, 2015[24]).

estimates on 17 micronutrients and micronutrient-related conditions, using 40 indicators across more than 150 countries (WHO, n.d. $[89]$ ) and includes only estimates which meet minimum standards of reliability (Jennings Aburto et al., 2013, p. 109[90]). However, as the database brings together studies conducted by various teams, comparability of evidence across and within countries may be hampered by inconsistent definitions and cut-off points for deficiency (Jennings Aburto et al., 2013[90]). Additionally, most of the data currently focuses on vitamin A, iodine and anaemia, with gaps on other micronutrient deficiencies (Development Initiatives, 2018, p. 54[20]).

\footnotetext{
${ }^{3}$ In addition, the estimates on the distribution of food consumption across households are typically based on household survey data from earlier years, and hence assume that the level of inequality in food consumption did not change in the meantime. Because of these limitations of the PoU estimates, more recent work has sought to complement these estimates with more fine-grained information on food insecurity experiences, based on survey data. This form of data collection allows for a higher degree of disaggregation by socio-economic characteristics; the estimates can also be used to validate measures of PoU. (FAO, IFAD, UNICEF, WFP, and WHO, 2020[22]). However, as with any indicator that is measured using survey data, the quality of the evidence for comparisons across different socio-economic subgroups is diminished when small sample sizes are used. For instance, food insecurity experience data collected using the Gallup World Poll, which generally has sample sizes between 1 000-5 000 respondents, were found to be "likely insufficient and underpowered to make comparisons across rural and urban regions, sub-nationally, or even by gender" (Lele et al., 2016, p. 46[92]).
} 


\section{Inconsistent methodologies may prevent comparison of available evidence}

As noted earlier, the low reporting rates of some SDG indicators do not necessarily reflect an absolute lack of evidence, but may rather reflect the difficulties in developing an internationally agreed methodology. For instance, both the indicator measuring the proportion of agricultural land area managed productively and sustainably (SDG 2.4.1) and the Food Loss Index (SDG 12.3.1) have reporting rates of $0 \%$ (Table 1). But some data on these issues is available and has been discussed in recent reports (OECD, 2019 [29]) (FAO, $\left.2019_{[30]}\right)$. More generally, some information is often available, but inconsistent methodologies make it difficult to compare across countries. Consistent methodologies are imperative for a global understanding of food system policy issues, as well as for engaging in cross-country comparisons (e.g. to benchmark good practices). In the context of the SDG indicators, a three-tier classification is used: Tier III indicators are those with no internationally established methodology, while Tier II and Tier I are distinguished based on the reporting rates (IAEG-SDGs, 2020, p. 2[31]). Following extensive coordination efforts, all SDG indicators under FAO custodianship now have internationally established methodologies. Many of these methodologies were only established recently, which partly explains the low reporting rates for some indicators. For many other indicators not included in the SDG indicator framework, internationally consistent methodologies are still lacking.

Biodiversity is another area where evidence gaps reflect not so much an absolute lack of information but rather the difficulty of comparing a wide array of indicators and methodologies (Bioversity International, $\left.2019_{[32]}\right)$. OECD work on biodiversity indicators has noted that very few indicators are used consistently across multiple countries (OECD, 2019[33]) (OECD, 2019[34]).

Internationally established methodologies do exist for reporting on two SDG indicators, preserving genetic resources in conservation facilities (2.5.1) and identifying at-risk-of-extinction local breeds (2.5.2), and with relatively good global reporting rates $(50.5 \%$ and $39.3 \%$, respectively) (FAO, 2020[15]). However, these indicators only capture a small aspect of biodiversity. One attempt to capture a wider number of aspects is the Agrobiodiversity Index developed by Bioversity International and the International Centre for Tropical Agriculture which aims to bring together data on "the agrobiodiversity that people sell and eat, the agrobiodiversity in their fields and lands, and the genetic resources that underpin them" (Bioversity International, 2018[35]). Given the importance of local context, biodiversity indicators are particularly prone to the problem of insufficient granularity noted earlier. Ideally, biodiversity indicators would use geospatially explicit data on land use and habitats, but this is currently limited (OECD, 2019 $\left.{ }_{[34]}\right)$.

\section{Evidence may be fragmented across different public and private actors}

In addition to evidence that is available but lacking in detail, evidence may often be fragmented across different actors (IAEG, 2014[36]) (SDSN TReNDS, 2017[37]) (SDSN TReNDS, 2019, p. 51[38]). For example, data may be fragmented across different public actors (e.g. different ministries or agencies, different levels of government), as well as across the public and private sector. When relevant data is held by the private sector, the complexity of food supply chains may be an additional factor creating fragmentation.

One example of fragmentation concerns the issue of healthier diets. Effective policies would need to start from an understanding of what consumers actually eat, how they choose, and how these choices could be influenced. This requires disaggregated information on what different people actually eat, linked to data on food composition and the food environment. Each of these three areas have their own data availability challenges. ${ }^{4}$ But in addition there is a challenge in linking these disparate data sources where they exist.

\footnotetext{
${ }^{4}$ The gold standard for understanding diets would be a nationally representative individual-level food intake survey, harmonised across countries, with the ability to disaggregate by age, gender and region; many researchers have lamented the absence of such data (Micha et al., 2018[61]) (Fanzo et al., 2020[4]). In addition to a lack of precise information on what people eat, information on the nutritional composition of food may also be lacking. Many countries and regions do not have food composition tables or databases, and when they do, these tend to be outdated and are not internationally harmonised (Micha et al., 2018[61]). Food composition databases typically face high lab test costs and do not have the level of detail needed to represent the actual composition of packaged food products; when data on actual packaged food products are available, it is a challenge to keep information up to date given rapid changes in product formulations (Giner and Brooks, 2019 ${ }_{[53]}$ ). The third component, the food environment which influences
} 
One issue is the need to match the concrete food items listed by individuals in a food intake survey to food composition tables listing nutritional properties. ${ }^{5}$ Food composition tables themselves require integration of both public and private data, particularly in the case of branded foods. This is not a trivial task, although examples of successful public-private partnerships exist. ${ }^{6}$

Another way in which synergies can be created between public and private efforts is through more widespread use of "open government data" (OGD), the practice of public institutions making their datasets available to the wider public. This allows citizens, civil society organisations and businesses to creatively use and combine these data, which may in turn lead to innovative ways of delivering public services (OECD, 2018[39]) (OECD, 2019[40]) (World Bank, 2021 $\left.{ }_{[41]}\right)$.

\section{Synergies, trade-offs, and spatial linkages are not always well understood}

The defining characteristic of a food systems approach is the awareness of possible interactions between elements that have historically often been considered in isolation (OECD, 2021 [1] ). A well-known example is the possible connection between nutrition and healthy diets on the one hand, and environmental sustainability on the other, investigated by an increasing number of studies (see e.g. Global Panel on Agriculture and Food Systems for Nutrition (2016[11]), HLPE (2017[5]), FAO (2018[42]), Willett et al. $\left(2019_{[14]}\right)$, SAPEA $\left(2020_{[12]}\right)$, among others).

Much progress has been made in clarifying these and other connections between the many interacting parts of food systems. At the same time, important gaps in understanding remain. All of the evidence gaps mentioned earlier directly impact analysts' ability to study interactions: for example, if sufficiently granular data is lacking on environmental or socio-economic outcomes, it will clearly be difficult to study the impact of a change in other parts of the food system on these outcomes in much detail; and if information on diets is lacking, it is difficult to assess their environmental impacts. These challenges are compounded by the need to create an integrated analysis across different dimensions, different sources of data and different levels of analysis (Liu et al., 2015[43]). For example, local land use change is shaped to a large extent by global dynamics (e.g. global demand for agricultural commodities), but global conditions in turn are influenced by local responses (e.g. expansion of agricultural land use), creating a need to understand global-to-local-to-global linkages (Hertel et al., 2019[44]). Integrated analysis also requires connecting biophysical and socio-economic information, which is not a trivial task (Liu et al., 2015[43]).

Despite limitations in the current evidence base, researchers have made progress in identifying synergies and trade-offs at a global level (see e.g. Valin et al. (2021 [45]) for a recent discussion in the context of the goal of achieving Zero Hunger). However, as emphasised by OECD (2021 $\left.{ }_{[1]}\right)$, deciding on a specific policy requires a detailed knowledge of synergies and trade-offs associated with concrete policy instruments. For example, understanding the environmental effects of dietary change at a fine-grained level requires traceability of product flows, as individual producers often differ strongly in their environmental footprint

consumer choices, similarly faces data availability issues. Information on food prices, physical access, product/vendor properties, marketing etc., is sparse (Giner and Brooks, 2019 [53]) (Baragwanath, 2021 [62]) (Placzek, 2021 [17]) (OECD, 2021 [1]) (Fanzo et al., 2020[4]) (Global Panel, 2017[86]) (Global Panel, 2015[85]) (Micha et al., 2018[61]) (Development Initiatives, 2018[20]) (HLPE, 2017[5]). In fact, even the appropriate methodology to assess food environments represents a current knowledge gap (Turner et al., 2017[87]).

${ }^{5}$ Guidelines and classification systems have been developed, notably the FAO/International Network of Food Data Systems (INFOODS) guidelines on food matching criteria (FAO/INFOODS, 2012[88]) and the FoodEx2 food classification and description system (Micha et al. (2018[61])).

\footnotetext{
${ }^{6}$ For instance, the United States Department of Agriculture (USDA) Branded Food Products Database (BFPDB) is the result of a collaboration between USDA and a number of private-sector, non-profit and academic partners. USDA also conducts a Food Acquisition and Purchase Survey (FoodAPS) as a means to collect food environment data, linking household food purchase and acquisition data (at and away from home) to food composition databases using Universal Product Code (UPC) barcodes (Baragwanath, 2021[62]). This demonstrates the potential to overcome the challenge of fragmentation of data across public and private actors to understand the healthfulness of diets and food environments. However, the USDA represents one of the most advanced food data systems in the world (Giner and Brooks, 2019 ${ }_{[53]}$ ) (Baragwanath, 2021 [62]). Many other countries struggle to achieve the same integration of disparate data sources, and purchasing privately-held data poses cost barriers to many governments (Placzek, 2021 [17]).
} 
(Poore and Nemecek, 2018[46]). As discussed in the next section, evidence on synergies and trade-offs, as well as on the effectiveness of policy instruments more broadly, is especially lacking.

\section{Evidence on the effectiveness of policy instruments is especially lacking}

Detailed evidence on the extent and characteristics of policy issues, collected using consistent methodologies, is necessary but not sufficient to tackle the policy challenges facing food systems. Often, major evidence gaps exist around the question of which policy interventions can effectively address a problem.

For example, it is well understood that a sizeable share of global food production is either lost in the supply chain or wasted at household level. Precise estimates are difficult, as emphasised by recent efforts by FAO on food loss (FAO, 2019) and UNEP on food waste (UNEP, 2021). Yet, a variety of approaches (including comparisons of calorie availability with observed weight gain) suggest that some $30 \%$ of global food production is lost or wasted ( (FAO, 2019 $\left.{ }_{[30]}\right)$; (UNEP, 2021 [47]); (Lopez Barrera and Hertel, 2021 [48])), which implies that reducing food loss and waste could have important benefits for food security and environmental sustainability. However, not much is known about the effectiveness of possible policy interventions to address food loss and waste, as well as about possible synergies and trade-offs with other objectives (Cattaneo et al., 2021 [49]). One recent review focusing on downstream food-waste reduction interventions (Reynolds et al., 2019[50]) could find only 17 peer-reviewed studies, of which only 13 quantified the resulting food waste reductions. These studies suggest that some interventions such as changing plate sizes in hospitality environments, changing nutritional guidelines in schools, and information campaigns may be effective, although it is unclear to what extent these initiatives can be scaled up and whether effects are long-lasting. Another review of interventions is provided by the EU Joint Research Centre (JRC), which developed an evaluation framework for actions to address food loss and waste and applied this framework to 91 initiatives reported by members of the EU Platform on Food Loss and Waste (FLW) (Caldeira, De Laurentiis and Sala, 2019[51]). More than half (49 out of 91) of the initiatives did not report any information on the amount of food waste prevented, while many of the other initiatives did not report a baseline against which the reduction could be measured. Information on the cost of the intervention was typically missing, making it impossible to assess the efficiency. Moreover, the interventions included in this study were mostly self-reported rather than derived from an independent assessment, and did not include control groups. Despite active interest from researchers, policy makers, and civil society in food loss and waste, there thus appear to be major evidence gaps when it comes to the effectiveness and efficiency of different policy interventions.

What is true for food loss and waste also holds for food systems more broadly: a major recent review of evidence to help support a transition to a sustainable food system for the European Union concluded that "[e]vidence of the need for concerted action is overwhelming, but evidence of what works in practical policy terms is scarce and often limited to specific contexts" (SAPEA, 2020, p. 158 ${ }_{[12]]}$.

Evidence on "what works" can come in many forms. Strictly speaking, it is impossible to know the effects of a specific policy intervention with certainty before the policy has been implemented - and even then, evaluating its effects might be difficult. But there are various ways to reduce the uncertainty around the likely effects.

Randomised controlled trials (RCTs) are routinely used in medical science, for example to determine the effectiveness of a new vaccine. Outcomes in a treatment group are compared with those in a control group. To reduce the possibility that other factors distort this comparison (e.g. selection bias where some people are more willing or more likely to receive treatment), the treatment is allocated randomly. The control group is often provided with a placebo, to avoid psychological factors from influencing the results. While RCTs are most commonly used for medical studies, it is possible to use the methodology to investigate questions in the social sciences. Over the past two decades, economists and other researchers have increasingly used RCTs to measure the effectiveness of various development interventions. This methodological innovation has greatly improved researchers' and practitioners' understanding of "what works", as recognised by the 2019 Nobel Prize in Economics awarded to Abhijit Banerjee, Esther Duflo and Michael Kremer for their pioneering work in this area. An RCT was used in France in 2016 to test the impact of different front-of-pack nutrition labels. Four different designs were tested on 1300 products in 60 retail stores, which were divided into different treatment groups (each group of stores testing one design) and a 
control group (stores not testing a simplified labelling system). The evidence gathered from this experiment provided support for the introduction of the Nutri-Score labelling system (Dubois et al., 2021 [52]) (Giner and Brooks, 2019[53]). There is considerable potential to increase the use of RCTs for food systems, including e.g. in the design of agricultural policies in developed countries (Behaghel, Macours and Subervie, 2019 [54]). RCTs provide high-quality evidence, although for social and economic questions there is always a question around the "external validity" of results - the extent to which RCT results from a particular setting hold in other settings (e.g. other countries). This is particularly relevant for food systems, given the large variation in conditions around the world. Conducting several RCTs in different settings can reduce the uncertainty and can shed light on the most important contextual factors.

RCTs are not always feasible. For example, analysts may want to retroactively evaluate policies which are already in place. Many policies are also by their nature hard to evaluate using an RCT, for example because they are necessarily implemented nation-wide or system-wide (e.g. environmental regulations, trade policies). Moreover, even where RCTs would be feasible in theory, they require considerable investments of time and money, which makes RCTs impractical in many settings. Fortunately, advances in statistical approaches now make it possible to still derive rigorous estimates of policy impacts in many of these cases, although this requires careful analysis (Angrist and Pischke, 2010[55]) (Athey and Imbens, 2017[56]) (Cunningham, 2021[57]).

In other cases, cross-country comparisons can be used. These require an international database of outcomes at the national level, as well as information on policies in place in these countries. International organisations such as the OECD have long played a key role in collecting and disseminating this type of information, e.g. through the OECD Agricultural Policy Monitoring and Evaluation reports (OECD, 2020[58]) and the OECD Review of Fisheries (OECD, 2020[59]).

Case studies might similarly provide useful insights. However, while a case study can provide a rich description of the context of a policy intervention and its effects, an important drawback is that it may not be clear to what extent those experiences can be generalised to other contexts. Nevertheless, when done well, case studies can be valuable, for example in creating a better qualitative understanding of causal mechanisms (Gerring, 2009[60]).

Models are an alternative way of reducing the uncertainty about the effects of a policy intervention. Rather than relying on ex post assessments, a model abstracts a complex reality into a simplified tool which can be used to conduct ex ante scenarios. Models are therefore especially useful in cases where direct experimental evidence is difficult to obtain, for example in tracing the likely global effects of trade policy reforms. However, the reliability of models depends on the strength of the theoretical underpinnings as well as the quality of the underlying data.

Uncertainty about the effects of interventions can be further reduced if insights from these different approaches reinforce each other, and when findings are consistent with what is known in other disciplines (e.g. about human psychology, organisational behaviour, environmental systems).

To evaluate a proposed policy intervention, it is not sufficient to know the direct effects of the intervention on one target objective only. Policies might have effects on other outcomes, either directly or indirectly. Understanding the full range of outcomes is important to avoid a situation where a policy intervention improves outcomes in one area only to worsen them in another. Policy coherence requires an understanding of such trade-offs, as well as of any potential synergies (where the intervention has positive effects on other outcomes). The desirability of a policy intervention will also depend on its cost and ease of implementation. Impact assessments (for example on the basis of cost-benefit analysis) can help collect the necessary evidence to make an informed decision (OECD, 2021 $\left.{ }_{[1]}\right)$.

Policy making must also take into account distributional consequences of a policy intervention, and must be consistent with the wider values held by the population. Hence, it is also important to understand the "interests" and "values" relevant to a policy decision, and evidence gaps regarding these issues can greatly complicate the process of creating alignment around policy change (OECD, $\left.2021_{[1]}\right)$. 


\section{A pragmatic approach focuses on where better evidence can make the biggest difference}

As the discussion above makes clear, there are numerous areas of food systems where better data and evidence would be desirable. At the same time, information will never be perfect: for example, even if abundant high-quality evidence existed about current and past conditions, there will always be uncertainty over future developments.

Yet even evidence on current and past conditions is costly and difficult to collect. For example, detailed agricultural censuses (which collect information on all farms and farmers in a country) provide high-quality data but come at a significant cost. ${ }^{7}$ In other areas, costs of data collection can be high too. For example, detailed individual food intake surveys are expensive, and hence are not conducted regularly (Giner and Brooks, 2019[53]) (Micha et al., 2018[61]) (Baragwanath, 2021 [62]). For the Sustainable Development Goals more broadly, it has been estimated that there is a budgetary shortfall of about USD 700 million per year in national statistical systems, leading to gaps and delays (SDSN TReNDS, 2019, p. $11_{[38]}$ ).

Budgetary limitations are not the only constraint on collecting high-quality evidence; these also require skilled staff (e.g. trained statisticians, data scientists). Moreover, not only may it be difficult to collect certain types of data or evidence, even the maintenance and use of existing data may be costly and difficult, e.g. due to costs of IT, data storage, use of specialised software, and retention of highly skilled permanent staff (Baragwanath, 2021 $\left.{ }_{[62]}\right)^{8}$

These constraints also hold for scientific evidence on causal mechanisms and evidence on policy effectiveness: greater precision and reliability requires financial resources and specialised skills. Moreover, by its very nature, scientific knowledge is continuously evolving - as are food systems themselves: as consumption patterns, production technologies and environmental conditions change, once-accurate information may become outdated.

For these reasons, policy decisions are always made under imperfect information. It would be unreasonable to expect to fill all evidence gaps completely, and it would be unreasonable to see this as a precondition for policy making. Rather, the question is which investments in data and evidence gathering can have the biggest impact in reducing the uncertainty policy makers face regarding food systems.

The prioritisation of evidence needs can be aided by a variety of different tools. For instance, prominent gaps can be identified using Evidence Gap Maps (EGM), initially developed by the International Initiative for Impact Evaluation (www.3ieimpact.org). An EGM is a table which visually represents the quantity and quality of available evidence on possible policy interventions and their outcomes. For example, Figure 1 shows part of an EGM for agricultural innovation (Lopez-Avila et al., 2017[63]). The full EGM lists various possible outcomes of agricultural innovation in the columns (knowledge, adoption, yields, etc.) and possible policy interventions in the rows (e.g. social networking and peer learning, demonstration plots, contract farming, etc.). Each cell is populated with "bubbles" representing studies on the link between the intervention and the outcome. Different colours of bubbles represent types of studies with varying levels of quality (e.g. green for high-quality systematic reviews) while the size of the bubble indicates the number of studies of this type. EGMs thus make it possible to see at a glance for which effects there is strong evidence, and which possible effects have not been studied at all or only have low-quality evidence. In addition to agricultural innovation, EGMs have been created for a variety of other food systems-related

\footnotetext{
${ }^{7} \mathrm{FAO}$ reports that the cost of agricultural censuses ranges from around USD 2 to more than USD 20 per farm holding in developing and transition countries (FAO, 2017[91]). Using a conservative estimate of USD 2 per farm holding, this suggests that a detailed agricultural census on the roughly 15 million farms in Bangladesh would cost at least USD 30 million, a large expense for a developing country. Even for high-income countries, investments are considerable. FAO reports costs in the range of EUR 2 to EUR 74 per farm holding in the EU; using a conservative estimate of EUR 10 per farm holding would imply a cost of EUR 100 million to conduct a census of the roughly 10 million farms in the EU. For this reason, detailed agricultural censuses are typically conducted once per decade, and complemented with less extensive surveys.

${ }^{8}$ Where surveys are used, an additional constraint may be the reluctance of respondents to share information, either because of reasons of confidentiality or because of an unwillingness to complete lengthy questionnaires. The latter imposes a limit on the level of detail and the frequency with which the same respondent can be surveyed.
} 
topics including agriculture and nutrition (Sparling et al., 2021[64]), agricultural financial risk (Barooah et al., 2017[65]), land use change and forestry programmes (Snilstveit et al., 2016[66]), youth and transferable skills (Rankin et al., 2015[67]), sustainable development (Phillips et al., 2017[68]), maternal, new born, and child health (Portela et al., 2017[69]), and forest conservation interventions (Puri et al., 2016[70]).

\section{Figure 1. Example of an Evidence Gap Map (EGM) on agricultural innovation}

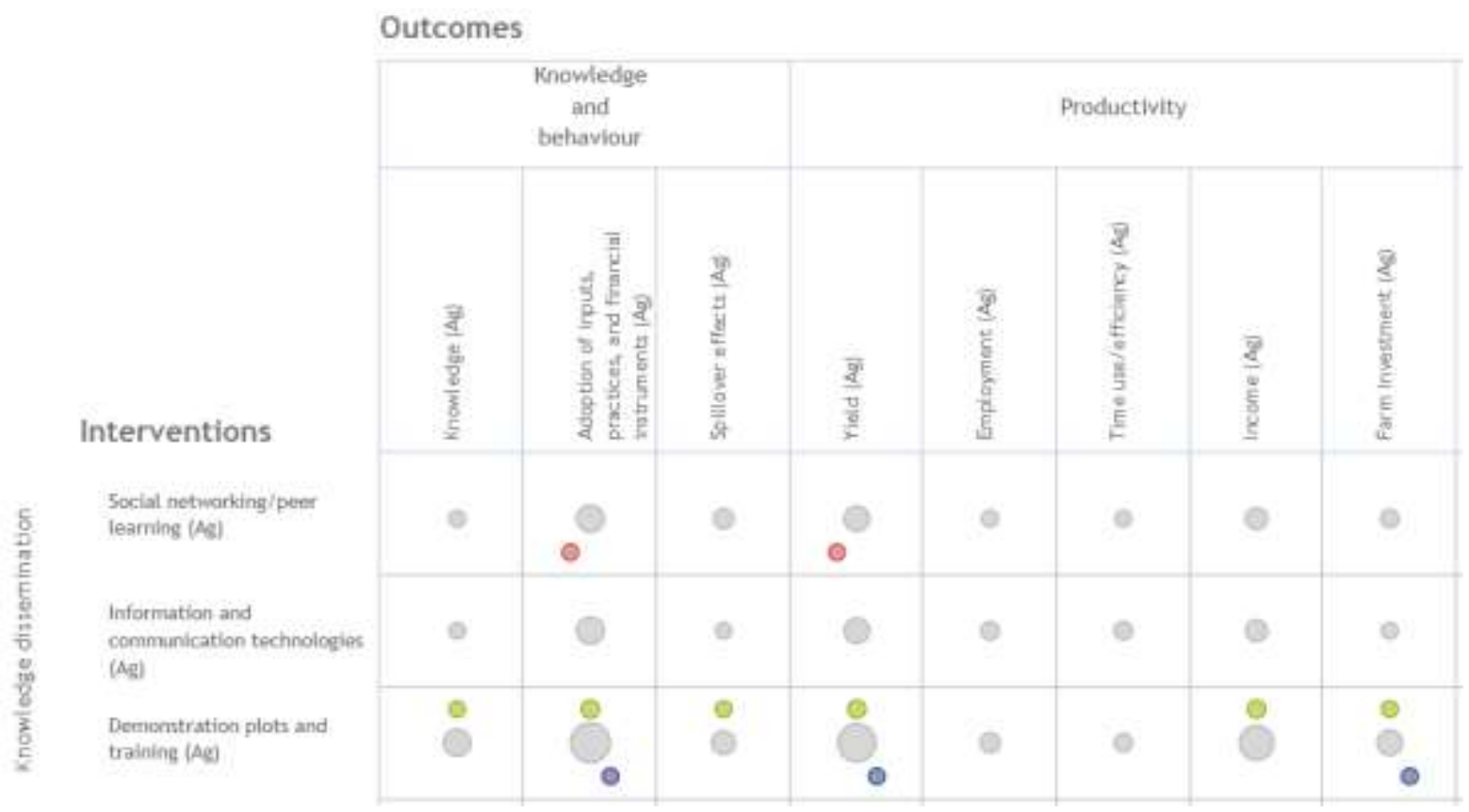

Note: Showing only a subset of interventions and outcomes. Grey bubbles refer to impact evaluations. Green, orange and red bubbles refer to systematic reviews with high (green), medium (orange) or low (red) confidence in conclusions about effects. Blue bubbles refer to protocols for systematic reviews (setting out ex ante how a systematic review will be conducted). The size of the bubble indicates the number of studies of that type.

Source: https://gapmaps.3ieimpact.org/evidence-maps/agricultural-innovation

In addition to EGMs, a range of other techniques exist to set research priorities (see e.g. Alston et al. $\left(1998_{[71]}\right)$ in the context of agricultural research). For both EGMs and other research priority setting techniques, a "theory of change" or conceptual framework and consultations with experts help with identifying where more data or evidence is needed. The joint work of the TReNDS initiative and Global Partnership for Sustainable Development Data (GPSDD) illustrates this practice through case studies in their series "What is the true value of data" (Neuner, 2018[72]), which discusses the returns on investment, impacts, and challenges of implementing data solutions like earth observation data (SDSN TReNDS, 2018[73]), censuses (SDSN TReNDS, 2018[74]) and the Living Standards Measurement Survey (SDSN TReNDS, 2018[75]).

While such prioritisations can help allocate scarce resources among different evidence gaps, the emergence of new tools and novel data sources makes it possible to fill gaps at lower cost and at a greater level of detail (World Bank, 2021 [41]). Digital tools in particular hold much promise for improving agricultural and agri-environmental policies (OECD, 2019[76] $)$ as well as for demand-side policies (e.g. policies to improve consumer health or to enable more sustainable consumption choices) (Baragwanath, 2021 [62] $)^{9}$ Examples include the use of apps as a low-cost and real-time method of asking consumers about their dietary intake, or the use of remote sensing (e.g. through satellites) to obtain highly granular, geospatially explicit earth observation data on e.g. biodiversity, land-use change, and water resources (Anderson et al., 2017[77]). The TReNDS/GPSDD case study mentioned earlier found that such programmes provide

\footnotetext{
${ }^{9}$ On the policy challenges related to the digital transformation of agriculture (including e.g. issues of data ownership and privacy), see Jouanjean et al. (2020[84]).
} 
estimated global economic benefits as high as USD 2 billion (SDSN TReNDS, 2018[73]). Another innovative approach is the use of web scraping and text mining. For example, for its 2019 State of Food and Agriculture report on food loss and waste $\left(F A O, 2019_{[30]}\right)$, FAO used web scraping to identify more than 20000 data points from more than 480 reports. ${ }^{10}$

In addition to technological innovation, institutional innovations can also help unlock more data and evidence. For example, firms (and farmers) may often be reluctant to share data about their operations publicly, but new institutional mechanisms can facilitate the disclosure of such information. An example is the work of CDP (www.cdp.net), an international non-profit which allows firms, cities, states or regions to disclose information on their impacts on climate change, water and forestry in exchange for a score ranging from $F$ (simply disclosing information) to $A$ (setting ambitious and meaningful targets to manage environmental risks) (CDP, n.d. [78]). This system allows for actors to determine the degree to which they feel comfortable revealing information, taking into consideration tangible and growing business benefits of disclosure that include protecting and improving reputation as well as tracking and benchmarking progress against peers (CDP, n.d. [79]). Currently roughly 10000 of the world's largest firms (representing over half of the value of global stock markets) disclose information on climate change, water, and forestry impacts through CDP. A wide range of other private and semi-private initiatives on sustainability exist, often in the form of labelling schemes (Gruère, 2013[80]).

Pragmatic approaches to filling evidence gaps should also avoid "reinventing the wheel", and instead should build on existing structures wherever possible. For example, the European Commission has proposed transforming the Farm Accountancy Data Network (FADN) into the Farm Sustainability Data Network (European Commission, 2020[81]). As FADN already employs a harmonised methodology to collect representative farm level microeconomic data, adapting this system to collect additional sustainability data could prove a pragmatic way of filling gaps. Similarly, short survey modules can often be added to existing household or agricultural surveys to shed light on under-studied topics. Recent work to calculate and compare the affordability of healthy diets around the world provides another example of creatively leveraging existing structures (Hirvonen et al., 2019[82]) (Bai et al., 2021 ${ }_{[83]}$ ): researchers used data originally collected by the World Bank's International Comparison Program to compare price levels and living standards internationally, and combined this data with other information sources to compute the daily cost of essential nutrients in 177 countries.

Finally, the availability of sound data and evidence by itself does not guarantee an evidence-based policy process. In the context of food systems, there are several myths and misconceptions which continue to circulate in public debate despite lacking a foundation in fact. However, a range of good practices exist to build a shared understanding of the facts during the process of policy development, including the use of regulatory impact assessments or input from scientific advisory bodies. Strengthening these mechanisms can help ensure that policies are based on the best available data and evidence (OECD, $\left.2021_{[1]}\right)$.

\section{Conclusion}

With only ten years left to realise the SDGs, the world urgently needs to develop effective policy responses to address food systems' "triple challenge" of providing food security and nutrition, ensuring livelihoods, and achieving environmental sustainability. The unprecedented shocks imposed on food systems by COVID-19 have further highlighted the urgency of addressing these problems.

The broad outlines of the challenges are clear, and in many cases evidence exists on how better policies can improve the performance of food systems. But there are also considerable gaps in data and evidence. Evidence may be missing, or not detailed enough; evidence may be generated using inconsistent methodologies, making it difficult to compare across countries; evidence may be available but fragmented across public and private actors. Moreover, evidence on policy effectiveness is often lacking, especially regarding synergies and trade-offs across different food systems outcomes.

10 See http://www.fao.org/datalab/website/web/food-losses-and-waste-data-non-conventional-sources (consulted 15 June 2021). 
Gathering additional data and evidence is costly and time-consuming, and requires specialised skills. It is not optimal to wait for all gaps to be filled. Policy making always occurs under less-than-perfect information, and waiting is itself a potentially costly decision. Rather, a pragmatic approach to overcoming evidence gaps focuses on where better evidence can make the biggest difference to reduce uncertainty for policy makers. Tools such as evidence gap maps (EGMs) can help to prioritise efforts. New technologies (e.g. digital tools) and institutional innovations can make it easier to overcome gaps. Moreover, wherever possible the effort to fill evidence gaps should build on existing infrastructure to avoid reinventing the wheel. 


\section{References}

Alston, J., G. Norton and P. Pardey (1998), Science Under Scarcity: Principles and Practice for Agricultural Research and Priority Setting, CAB International.

Anderson, K. et al. (2017), "Earth observation in service of the 2030 Agenda for Sustainable Development", Geo-spatial Information Science, https://doi.org/10.1080/10095020.2017.1333230, pp. 77-96.

Angrist, J. and J. Pischke (2010), "The credibility revolution in empirical economics: How better research design is taking the con out of econometrics", Journal of Economic Perspectives, Vol. 24/2, pp. 3-30, http://dx.doi.org/10.1257/jep.24.2.3.

Athey, S. and G. Imbens (2017), "The State of Applied Econometrics: Causality and Policy Evaluation", Journal of Economic Perspectives, Vol. 31/2, pp. 3-32, http://dx.doi.org/10.1257/jep.31.2.3.

Bai, Y. et al. (2021), "Cost and affordability of nutritious diets at retail prices: Evidence from 177 countries", Food Policy, Vol. 99, p. 101983, http://dx.doi.org/10.1016/j.foodpol.2020.101983.

Baragwanath, T. (2021), "Digital opportunities for demand-side policies to improve consumer health and the sustainability of food systems", OECD Food, Agriculture and Fisheries Papers, No. 148, OECD Publishing, Paris, https://dx.doi.org/10.1787/bec87135-en.

Barooah, B. et al. (2017), Understanding financial agricultural risk for smallholder farmers in developing countries: what do we know and not know?, International Initiative for Impact Evaluation (3ie), https://www.3ieimpact.org/sites/default/files/2019-01/egm9-ag-risk 0.pdf.

Behaghel, L., K. Macours and J. Subervie (2019), "How can randomised controlled trials help improve the design of the common agricultural policy?", European Review of Agricultural Economics, Vol. 46/3, pp. 473-493, https://doi.org/10.1093/erae/jbz021.

Bene, C. et al. (2018), "When food systems meet sustainability - Current narratives and implications for actions", World Development, Vol. 113, pp. 116-130, https://doi.org/10.1016/j.worlddev.2018.08.011.

Bioversity International (2019), Agrobiodiversity Index Report 2019: risk and resilience, https://cgspace.cgiar.org/handle/10568/100820 (accessed on 15 June 2021).

Bioversity International (2018), The Agrobiodiversity Index: Methodology Report v.1.0., https://cgspace.cgiar.org/handle/10568/106478 (accessed on 15 June 2021).

Blandford, D. (2007), "Information Deficiencies in Agricultural Policy Design, Implementation and Monitoring", OECD Food, Agriculture and Fisheries Papers, No. 6, OECD Publishing, Paris, https://dx.doi.org/10.1787/067228574571.

Caldeira, C., V. De Laurentiis and S. Sala (2019), Assessment of food waste preventation actions: development of an evaluation framework to assess the performance of food waste prevention actions, Publications Office of the European Union, http://dx.doi.org/10.2760/9773.

Cattaneo, A. et al. (2021), "Reducing food loss and waste: Five challenges for policy and research”, Food Policy, Vol. 98, https://doi.org/10.1016/j.foodpol.2020.101974. 
CDP (n.d.), Companies Scores, https://www.cdp.net/en/companies/companies-scores (accessed on March 2021).

CDP (n.d.), Why disclose as a company, https://www.cdp.net/en/companies-discloser (accessed on March 2021).

Cunningham, S. (2021), Causal Inference: The Mixtape, Yale University Press.

Development Initiatives (2018), 2018 Global Nutrition Report: Shining a light to spur action on nutrition, Development Initiatives, https://www.unscn.org/uploads/web/news/2018-GlobalNutrition-Report.pdf.

Dubois, P. et al. (2021), "Effects of front-of-pack labels on the nutritional quality of supermarket food purchases: evidence from a large-scale randomized controlled trial", Journal of the Academy of Marketing Science, Vol. 49/1, pp. 119-138, http://dx.doi.org/10.1007/s11747-02000723-5.

European Commission (2020), The CAP reform's compatibility with the Green Deal's ambition, https://ec.europa.eu/info/news/cap-reforms-compatibility-green-deals-ambition-2020-may20 en (accessed on March 2021).

FABLE (2019), Pathways to Sustainable Land-Use and Food Systems: 2019 Report of the FABLE Consortium, IIASA and SDSN, https://www.foodandlandusecoalition.org/wpcontent/uploads/2019/09/Fableinterimreport EU low.pdf.

Fanzo, J. et al. (2020), "The Food Systems Dashboard is a new tool to inform better food policy", Nature Food, Vol. 1, http://dx.doi.org/10.1016/j.agsy.2020.102901.

FAO (2020), Factsheets on the 21 SDG indicators under FAO custodianship: A highlight of the main indicators with the greatest gaps in country reporting, FAO, https://doi.org/10.4060/ca8958en.

FAO (2019), The State of Food and Agriculture 2019: Moving forward on food loss and waste reduction, http://www.fao.org/3/ca6030en/ca6030en.pdf.

FAO (2018), Sustainable food systems: Concept and framework, http://www.fao.org/3/ca2079en/CA2079EN.pdf.

FAO (2018), The future of food and agriculture: Alternative pathways to 2050, http://www.fao.org/3/18429EN/i8429en.pdf (accessed on 4 July 2019).

FAO (2017), "World Programme for the Census of Agriculture 2020: Volume 2 Operational Guidelines (Draft)", FAO Statistical Development Series 16, https://unstats.un.org/unsd/statcom/48th-session/documents/BG-Agriculture-E.pdf.

FAO, IFAD, UNICEF, WFP, and WHO (2020), The State of Food Security and Nutrition in the World 2020. Transforming food systems for afforable healthy diets, FAO, https://doi.org/10.4060/ca9692en.

FAO/INFOODS (2012), Guidelines for Food Matching Verson 1.2, FAO, http://www.fao.org/3/ap805e/ap805e.pdf.

Gerring, J. (2009), "The case study: What it is and what it does", Oxford Handbook of Political Science. 
Giner, C. and J. Brooks (2019), "Policies for encouraging healthier food choices", OECD Food, Agriculture and Fisheries Papers, No. 137, OECD Publishing, Paris, https://dx.doi.org/10.1787/11a42b51-en.

Gladek, E. et al. (2017), The Global Food System: An Analysis, https://www.metabolic.nl/publications/global-food-system-an-analysis-pdf/.

Global Panel (2017), Improving Nutrition Through Enhanced Food Environments, Global Panel on Agriculture and Food Systems for Nutrition, http://glopan.org/sites/default/files/Downloads/FoodEnvironmentsBrief.pdf.

Global Panel (2015), Improved Metrics and data are needed for effective food system policies in the post-2015 era, Global Panel on Agriculture and Food Systems for Nutrition, https://assets.publishing.service.gov.uk/media/59e09e73ed915d6aaafc2ea0/Metrics Brief.pdf

Global Panel on Agriculture and Food Systems for Nutrition (2016), Food systems and diets: Facing the challenges of the 21st century, https://glopan.org/sites/default/files/ForesightReport.pdf.

Gruère, G. (2013), "A Characterisation of Environmental Labelling and Information Schemes", OECD Environment Working Papers, No. 62, OECD, Paris, https://www.oecdilibrary.org/environment-and-sustainable-development/a-characterisation-of-environmentallabelling-and-information-schemes $5 \mathrm{k} 3 \mathrm{z} 11 \mathrm{hpdgq} 2-\mathrm{en}$.

Hertel, T. et al. (2019), A review of global-local-global linkages in economic land-use/cover change models, Institute of Physics Publishing, http://dx.doi.org/10.1088/1748-9326/ab0d33.

Hill, B. and D. Bradley (2015), Comparison of Farmer's Incomes in the EU Member States Study for the European Parliament, European Union.

Hirvonen, K. et al. (2019), "Affordability of the EAT - Lancet reference diet: a global analysis", The Lancet Global Health 19, pp. 1-8, http://dx.doi.org/10.1016/S2214-109X(19)30447-4.

HLPE (2017), Nutrition and Food Systems, High Level Panel of Experts on Food Security and Nutrition of the Committee on World Food Security, http://www.fao.org/fileadmin/user upload/hlpe/hlpe documents/HLPE Reports/HLPE-Report12 EN.pdf.

IAEG (2014), A world that counts: Mobilising the data revolution for sustainable development, United Nations.

IAEG-SDGs (2020), Tier Classification for Global SDG Indicators, https://unstats.un.org/sdgs/files/Tier\%20Classification\%20of\%20SDG\%20Indicators 17\%20 J uly\%202020 web.v3.pdf.

Jennings Aburto, N. et al. (2013), "An evaluation of a global vitamin and mineral nutrition surveillance system", Archivos Latinoamericanos de Nutrición, https://www.alanrevista.org/ediciones/2013/2/art-1/\#, pp. 105-113.

Jouanjean, M. et al. (2020), "Issues around data governance in the digital transformation of agriculture : The farmers' perspective", OECD Food, Agriculture and Fisheries Papers, No. 146, OECD Publishing, Paris, https://dx.doi.org/10.1787/53ecf2ab-en. 
Lele, U. et al. (2016), Measuring Food and Nutrition Security: An Independent Technical Assessment and User's Guide for Existing Indicators, http://www.fsincop.net/topics/fns(accessed on 15 June 2021).

Liu, J. et al. (2015), Systems integration for global sustainability, American Association for the Advancement of Science, http://dx.doi.org/10.1126/science.1258832.

Lopez Barrera, E. and T. Hertel (2021), "Global food waste across the income spectrum: Implications for food prices, production and resource use", Food Policy, Vol. 98, https://doi.org/10.1016/j.foodpol.2020.101874.

Lopez-Avila, D. et al. (2017), Agricultural Innovation: An evidence gap map, International Initiative for Impact Evaluation (3ie), https://www.3ieimpact.org/sites/default/files/201901/EGM12-Ag-innovation.pdf.

Micha, R. et al. (2018), "Globala Dietary Surveillance: Data Gaps and Challenges", Food and Nutrition Bulletin, Vol. 39/2, pp. 175-205, http://dx.doi.org/10.1177/03795721177529.

Neuner, J. (2018), What is the true value of data? New series on the return on investment of data interventions, https://www.sdsntrends.org/blog/2018/9/27/return-investment-data-casestudies-launch?rq=investing (accessed on January 2021).

OECD (2021), Making Better Policies for Food Systems, OECD Publishing, Paris, https://dx.doi.org/10.1787/ddfba4de-en.

OECD (2020), Agricultural Policy Monitoring and Evaluation 2020, OECD Publishing, Paris, https://dx.doi.org/10.1787/928181a8-en.

OECD (2020), OECD Review of Fisheries 2020, OECD Publishing, Paris, https://dx.doi.org/10.1787/7946bc8a-en.

OECD (2020), Taxation in Agriculture, OECD Publishing, Paris, https://dx.doi.org/10.1787/073bdf99-en.

OECD (2020), Updating and improving OECD agri-environmental indicators: A progress report, http://COM/TAD/CA/ENV/EPOC(2018)6/REV4.

OECD (2019), Agricultural Policy Monitoring and Evaluation 2019, OECD Publishing, Paris, https://dx.doi.org/10.1787/39bfe6f3-en.

OECD (2019), Digital Opportunities for Better Agricultural Policies, OECD Publishing, Paris, https://dx.doi.org/10.1787/571a0812-en.

OECD (2019), Innovation, Productivity and Sustainability in Food and Agriculture: Main Findings from Country Reviews and Policy Lessons, OECD Food and Agricultural Reviews, OECD Publishing, Paris, https://dx.doi.org/10.1787/c9c4ec1d-en.

OECD (2019), Innovation, Productivity and Sustainability in Food and Agriculture: Main Findings from Country Reviews and Policy Lessons, OECD Food and Agricultural Reviews, OECD Publishing, Paris, https://dx.doi.org/10.1787/c9c4ec1d-en.

OECD (2019), Measuring Distance to the SDG Targets 2019: An Assessment of Where OECD Countries Stand, OECD Publishing, Paris, https://dx.doi.org/10.1787/a8caf3fa-en. 
OECD (2019), The Path to Becoming a Data-Driven Public Sector, OECD Digital Government Studies, OECD Publishing, Paris, https://dx.doi.org/10.1787/059814a7-en.

OECD (2019), Trends and Drivers of Agri-environmental Performance in OECD Countries,

OECD Publishing, Paris, https://dx.doi.org/10.1787/b59b1142-en.

OECD (2019), Updating and Improving OECD Agri-environmental Indicators, http://COM/TAD/CA/ENV/EPOC(2018)6/REV2.

OECD (2018), Open Government Data Report: Enhancing Policy Maturity for Sustainable Impact, OECD Digital Government Studies, OECD Publishing, Paris, https://dx.doi.org/10.1787/9789264305847-en.

OECD (2003), Farm Household Income: Issues and Policy Responses, OECD Publishing, Paris, https://dx.doi.org/10.1787/9789264099678-en.

Parsons, K. and C. Hawkes (2019), Brief 5: Policy Coherence in Food Systems, Centre for Food Policy, https://www.city.ac.uk/ data/assets/pdf file/0018/504621/7643 Brief5 Policy coherence in food systems WEB SP.pdf.

Parsons, K. and C. Hawkes (2018), Connecting food systems for co-benefits: how can food systems combine diet-related health with environmental and economic policy goals?, World Health Organisation, https://openaccess.city.ac.uk/id/eprint/21042/.

Phillips, D. et al. (2017), A Map of Evidence Maps Relating to Sustainable Development in Lowand Middle-Income Countries, https://cedilprogramme.org/wp-content/uploads/2018/01/AMap-of-Evidence-Maps-Relating-to-Sustainable-Development-in-Low-and-Middle-IncomeCountries.pdf.

Placzek, O. (2021), "Socio-economic and demographic aspects of food security and nutrition", OECD Food, Agriculture and Fisheries Papers, No. 150, OECD Publishing, Paris, https://dx.doi.org/10.1787/49d7059f-en.

Poore, J. and T. Nemecek (2018), "Reducing food's environmental impacts through producers and consumers", Science, Vol. 360/6392, pp. 987-992, http://dx.doi.org/10.1126/science.aaq0216.

Portela, A. et al. (2017), Social, behavioral and community engagement interventions for reproductive, maternal, newborn and child health: An evidence gap map, Internation Initiative for Impact Evaluation (3ie), https://www.3ieimpact.org/sites/default/files/2019-01/EGM-11RMNCH 1.pdf.

Puri, J. et al. (2016), Examining the evidence base for forest conservation interventions, International Initiative for Impact Evaluation (3ie), https://www.3ieimpact.org/sites/default/files/2019-01/egm-4-forest-conservation 1.pdf.

Rankin, K. et al. (2015), Youth and tranferable skills: an evidence gap map, International Initiative for Impact Evaluation (3ie), https://www.3ieimpact.org/sites/default/files/201901/egm2-youth and transferable skills.pdf.

Reynolds, C. et al. (2019), "Review: Consumption-stage food waste reduction interventions What works and how to design better interventions", Food Policy, Vol. 83/February 2019, pp. 7-27, https://doi.org/10.1016/j.foodpol.2019.01.009. 
SDSN TRENDS (2019), Counting on the World to Act: A roadmap for governments to achieve modern data systems for sustainable development, https://countingontheworld.sdsntrends.org/static/files/19COTW.pdf.

SDSN TReNDS (2019), Counting on The World to Act: A Roadmap for Governments to Achieve Modern Data Systems for Sustainable Development.

SDSN TReNDS (2018), Household Surveys Shape Policy Investments, SDSN TReNDS and GPSDD, https://static1.squarespace.com/static/5b4f63e14eddec374f416232/t/5bef3a6c8a922d3d3245 f945/1542404718607/CaseStudy LivingStandardsMeasurementSurvey Nov2018.pdf.

SDSN TReNDS (2018), Landsat's Earth Observation Data Support Disease Prediction, Solutions to Pollution, and More, SDSN TReNDS and GPSDD, https://static1.squarespace.com/static/5b4f63e14eddec374f416232/t/5bacd7f2b208fc854181 7444/1538054151334/CaseStudy Landsat Sept2018.pdf.

SDSN TReNDS (2018), Valuation of the New Zealand Census, SDSN TReNDS and GPSDD, https://static1.squarespace.com/static/5b4f63e14eddec374f416232/t/5bef3214aa4a999d49469 0992/1542402652169/CaseStudy NewZealandCensus Nov2018.

SDSN TReNDS (2017), Counting on the world: Building modern data systems for sustainable development.

Snilstveit, B. et al. (2016), Land-use change and forestry programmes: Evidence on the effects on greenhouse gas emissions ans food security, International Initiative for Impact Evaluation (3ie), https://www.3ieimpact.org/sites/default/files/2019-01/egm3-landuse-forest 1.pdf.

Sparling, T. et al. (2021), "Understanding Pathways Between Agriculture, Food Systems, and Nutrition: An Evidence and Gap Map of Research Tools, Metrics, and Methods in the Last 10 Years", Advances in Nutrition, https://doi.org/10.1093/advances/nmaa158, pp. 1-15.

TEEB (2018), Measuring what matters in agriculture and food systems: A synthesis report, http://teebweb.org/wp-content/uploads/2018/10/Layout synthesis sept.pdf.

Turner, C. et al. (2017), Concepts and methods for food environment research in low and middle income countries, Agriculture, Nutrion and Health Academy Food Environments Working Group (ANH-FEWG). Innovative Methods and Metrics for Agriculture and Nutrition Actions (IMMANA) programme, https://anhacademy.org/sites/default/files/FEWG TechnicalBrief low.pdf.

UNEP (2021), Food Waste Index Report, United Nations Environment Programme, https://www.unep.org/resources/report/unep-food-waste-index-report-2021.

UNEP/SFSP (2019), Collaborative Framework for Food Systems Transformation A multistakeholder pathway for sustainable food systems, United Nations Environment Programme, http://www.oneplanetnetwork.org/initiative/setting-table-our-children-improving-governancefood-systems- (accessed on 5 February 2020).

Valin, H. et al. (2021), Achieving Zero Hunger by 2030: A Review of Quantitative Assessments of Synergies and Tradeoffs amongst the UN Sustainable Development Goals, Scientific Group of the UN Food Systems Summit, https://sc-fss2021.org/ (accessed on 15 June 2021).

Wanner, N. et al. (2014), Refinements to the FAO Methodology for Estimating the Prevalence of Undernourishment Indicator, FAO, http://www.fao.org/3/a-i4046e.pdf. 
WHO (n.d.), Vitamin and Mineral Nutrition Information System (VMNIS),

https://www.who.int/teams/nutrition-and-food-safety/databases/vitamin-and-mineral-nutritioninformation-system (accessed on March 2021).

Willett, W. et al. (2019), Food in the Anthropocene: the EAT-Lancet Commission on healthy diets from sustainable food systems, Lancet Publishing Group, http://dx.doi.org/10.1016/S0140-6736(18)31788-4.

World Bank (2021), World Development Report 2021: Data for Better Lives, The World Bank, http://dx.doi.org/10.1596/978-1-4648-1600-0. 


\section{OECD FOOD, AGRICULTURE AND FISHERIES PAPERS}

This report was declassified by the Working Party on Agricultural Policies and Markets in July 2021 and was prepared for publication by the OECD Secretariat and was prepared for publication by the OECD Secretariat.

This report, as well as any data and any map included herein, are without prejudice to the status of or sovereignty over any territory, to the delimitation of international frontiers and boundaries and to the name of any territory, city or area.

The statistical data for Israel are supplied by and under the responsibility of the relevant Israeli authorities. The use of such data by the OECD is without prejudice to the status of the Golan Heights, East Jerusalem and Israeli settlements in the West Bank under the terms of international law.

Comments are welcome and can be sent to tad.contact@oecd.org. 